\title{
Winter air pollution and respiratory function
}

\section{Lippmann}

It is neither easy nor inexpensive to find significant air pollution health effects in contemporary populations in economically advanced countries with relatively clean air

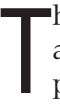
here has been growing concern about the effects of community air pollution on children for several reasons. These include:

(1) A rapidly growing and generally coherent body of epidemiological studies showing statistically significant (albeit small) increases in relative risk for particulate matter (PM) associated mortality and morbidity, as well as relatively large ozone associated functional decrements

(2) A rapidly growing prevalence of asthma and wheeze among children, and a recognition that such children are at greater risk for air pollution related health effects than other children.

(3) A recognition that children receive greater lung doses of airborne pollutants than adults because they spend more of their time in vigorous activity out of doors and breathe air more deeply into their smaller lungs.

In the paper entitled "Acute effects of winter air pollution on respiratory function in schoolchildren in southern England" by Peacock et al in this issue, authors extended their earlier investigation of the effects of summertime air pollutant exposure in children from the same area in southern England. ${ }^{2}$

In their previous study of summertime exposures, the authors reported very small, but statistically significant negative associations between the mass concentration of PM less than $10 \mu \mathrm{m}$ in aerodynamic diameter $\left(\mathrm{PM}_{10}\right)$, and forced expiratory volume in 0.75 seconds $\left(\mathrm{FEV}_{0.75}\right)$ and forced vital capacity (FVC), but no evident associations with ozone $\left(\mathrm{O}_{3}\right)$ or nitrogen dioxide $\left(\mathrm{NO}_{2}\right)$. For the wintertime study described in this issue, they relied on peak expiratory flow rate (PEFR) measured with mini-Wright meters provided for each child rather than on $\mathrm{FEV}_{0.75}$ and FVC measured by spirometry, and reported no clear PEFR associations with any of the measured air pollutants $\left(\mathrm{PM}_{10}, \mathrm{NO}_{2}, \mathrm{O}_{3}, \mathrm{SO}_{2}\right.$, and $\left.\mathrm{SO}_{4}{ }^{2-}\right)$. They did, however, note that $\mathrm{PM}_{10}$ was associated with decrements in PEFR greater than $20 \%$ in children with wheeze.

The use of the generally less precise measure of PEFR rather than spirometry determined $\mathrm{FEV}_{0.75}$ was probably not a reason for the failure to find much in the way of significant association between ambient pollution and lung function. The authors themselves pointed out that they had achieved a lower coefficient of variation for their PEFR measurements $(16 \%)$ in the wintertime study than they had achieved in their summertime spirometric measurements $(21 \%){ }^{2}$ Lippmann and Spektor $^{3}$ compared mini-Wright PEFR with spirometric PEFR measurements in children demonstrating $\mathrm{O}_{3}$ associated PEFR decrements, and reported close agreement among the two independent measurements.

The more likely reasons for the paucity of significant findings in this wintertime study include:

(1) The very low pollutant concentrations. The 90th centile values were only about $33 \mu \mathrm{g} / \mathrm{m}^{3}$ for 24 hour average $\mathrm{PM}_{10}, 35 \mathrm{ppb}$ for 8 hour $\mathrm{O}_{3}$, $29 \mathrm{ppb}$ for 24 hour $\mathrm{NO}_{2}$, and $11 \mathrm{ppb}$ for 24 hour $\mathrm{SO}_{2}$.
(2) A presumptively smaller amount of outdoor time and activity level due to the lower temperatures and many fewer wintertime daily hours of sunlight in southern England.

The observation of an association between a significant drop in PEFR and $\mathrm{PM}_{10}$ in children with wheeze is about all that could have been expected given the study design, the size and nature of the population being studied, and the levels of ambient air pollution.

One message to take away from this study is that finding significant air pollution health effects in contemporary populations in economically advanced countries with relatively clean air is not easy or inexpensive. In the Peacock et al wintertime study, with an experienced team, state of the art air monitoring employed on a daily basis, and with highly motivated student participants, school personal, and scientific staff, it was still not possible to come up with very definitive associations. Future investigations should be based on targets of opportunity with circumstances more favourable to the establishment of significant exposure-response relations.

\section{ACKNOWLEDGEMENTS}

Dr Lippmann's research is supported by the Particulate Matter Health Effects Research Center supported by the US Environmental Protection Agency (Grant No. R 827351), and by the National Institute of Environmental Health Sciences Center Grant (NIEHS), NIH (Grant No. ES-00260)

Occup Environ Med 2003;60:81

\section{Author's affiliation}

M Lippmann, New York University School of Medicine, Tuxedo, New York, USA

Correspondence to: Dr M Lippmann, Professor of Environmental Medicine, New York University School of Medicine, Tuxedo, NY 10987, USA: lippmann@env.med.nyu.edu

\section{REFERENCES}

1 Peacock JL, Symonds P, Jackson P, et al. Acute effects of winter air pollution on respiratory function in schoolchildren in southern England. Occup Environ Med 2003:60:82-9

2 Scarlett JF, Abot KJ, Peacock JL, et al. Acute effects of summer air pollution on respiratory function in primary school children in southern England. Thorax 1996;51:1109-14.

3 Lippmann M, Spektor DM. Peak flow rate changes in $\mathrm{O}_{3}$-exposed children: spirometry vs. miniWright flow meters. J Expos Anal Environ Epidemiol 1998;8:101-7. 